\title{
Efficacy of allylestrenol combined with ritodrine on threatened premature labor and its influence on inflammatory factors in peripheral blood
}

\author{
QING LI*, CHUNHUA LI* and HONGMEI JIN \\ Department of Obstetrics, Qingpu Branch of Zhongshan Hospital Affiliated to Fudan University, \\ Shanghai 201700, P.R. China
}

Received September 13, 2019; Accepted November 11, 2019

DOI: $10.3892 / \mathrm{etm} .2019 .8273$

\begin{abstract}
Efficacy of allylestrenol combined with ritodrine on threatened premature labor (TPTL) and its influence on inflammatory factors in peripheral blood were investigated. A total of 206 cases of TPTL patients from 2014 to 2016 were collected in Zhongshan Hospital Affiliated to Fudan University, and 106 cases were treated with allylestrenol combined with ritodrine as a research group and 100 cases were treated with allylestrenol combined with magnesium sulfate as a control group. General information of patients was collected, and changes in the expression levels of IL-17, IL-10 and IL- 6 were detected by enzyme-linked immunosorbent assay. Prolonged pregnancy time, success rate of fetal protection and average delivery time of patients were recorded. The adverse pregnancy conditions were compared, including the Apgar score of newborns, birth weight and adverse conditions, and postpartum hemorrhage volume and postpartum hospital stays in the two groups were recorded. Prolonged pregnancy time, success rate of fetal protection and average delivery time in the research group were significantly higher than those in the control group $(\mathrm{P}<0.05)$. After treatment, the levels of IL-17, IL-10 and IL-6 in serum of the two groups were significantly lower than those before treatment $(\mathrm{P}<0.05)$, and were significantly lower in the research group than in the control group $(\mathrm{P}<0.05)$. The average neonatal weight and Apgar score in the research group were significantly better than those in the control group $(\mathrm{P}<0.05)$. Postpartum hemorrhage, postpartum hospital stays and incidence rate of toxic side effects, neonatal death, malformation and asphyxia in the research group were
\end{abstract}

Correspondence to: Dr Hongmei Jin, Department of Obstetrics, Qingpu Branch of Zhongshan Hospital Affiliated to Fudan University, 1158 Park East Road, Shanghai 201700, P.R. China

E-mail: g2b96h@163.com; jinhm168@126.com

*Contributed equally

Key words: allylestrenol, ritodrine, threatened premature labor, efficacy, IL-17, IL-10, IL-6 significantly lower than those in the control group $(\mathrm{P}<0.05)$. Allylestrenol combined with ritodrine can significantly reduce the expression levels of IL-17, IL-10 and IL-6 in TPTL, reduce adverse pregnancy conditions, prolong gestational weeks, and has higher safety and better application value.

\section{Introduction}

Threatened premature labor (TPTL) is a sign of giving birth in the middle and late stages of pregnancy before normal delivery $(<37$ weeks). It is reported that $65 \%$ of pregnant women with TPTL will give birth prematurely (before 37 weeks) (1), while $\sim 30 \%$ of hospitalized patients related to pregnancy are due to TPTL (2), and premature labor is still the leading cause of neonatal death and attack $(3,4)$. Some studies have shown that $\sim 30 \%$ of premature labor is the result of spontaneous premature labor, and only $\sim 10-15 \%$ of women with symptoms of premature labor will give birth within the next 2-7 days (5). Finding more effective treatment methods for premature labor is a serious problem that needs to be faced clinically.

Allylestrenol (AT) is an artificially synthesized progesterone, which can effectively treat abortion, TPTL, intrauterine growth restriction (6). Some studies have pointed out that AT has selective $\beta$-adrenergic effect mediated by nerves on myometrium $\beta 2$ receptor, reducing myometrium activity, thus rapidly and effectively relaxing hypertonic myometrium within $24 \mathrm{~h}$, and avoiding life-threatening emergencies of mothers, such as pulmonary edema and myocardial ischemia. Therefore, AT is a drug with minimal side effects and good patient compliance in progesterone use $(7,8)$. Ritodrine (RD) can effectively inhibit the contraction of uterine smooth muscle, reduce uterine activity and prolong pregnancy, and is a commonly used anti-uterine contraction drug for TPTL treatment (9). Some studies have comfirmed that AT combined with $\mathrm{RD}$ in the treatment of habitual abortion has achieved better efficacy than that of AT alone (10). In addition, studies have also verified that the initiation of labor is closely related to the regulation of inflammatory factors. Progesterone can maintain pregnancy by mediating the expression of relevant inflammatory factors, which can not only control the symptoms of premature labor, but also eliminate the real causes of labor (11). 
Therefore, through prospective analysis, this study explores the efficacy of AT combined with RD on TPTL and its influence on inflammatory factors in peripheral blood, so as to provide reference for clinical treatment of TPTL.

\section{Patients and methods}

Patient data. Data of 206 patients with TPTL admitted to Zhongshan Hospital Affiliated to Fudan University from January 2017 to July 2018 were prospectively analyzed. They were aged 20-40 years, and were divided into two groups according to different drug application methods. Among them, 106 patients received AT combined with RD (research group) and 100 patients received AT combined with magnesium sulfate $\left(\mathrm{MgSO}_{4}\right)$ (control group). Inclusion criteria were as follows: cases conformed to TPTL diagnostic criteria, patients with complete clinical data, those who did not use other combined drugs, those with no contraindication for continuing pregnancy or using fetal protection drugs. Exclusion criteria were as follows: patients with abnormal heart, liver, lung and kidney functions, patients with hypertension, diabetes, hyperthyroidism and other diseases, multiple births, polyhydramnios, congenital malformation of children, and patients with mental diseases or abnormal brain judgment. This study informed all patients and their families by letter or telephone and they signed an informed consent. The study was approved by the Ethics Committee of Qingpu Branch of Zhongshan Hospital Affiliated to Fudan University (Shanghai, China).

Intervention methods. Pregnant women were injected dexamethasone $6 \mathrm{mg}$ intramuscularly after admission, $12 \mathrm{~h}$ each time, 4 times. The control group was injected with $\mathrm{AT}+\mathrm{MgSO}_{4}$. Treatment: $\mathrm{MgSO}_{4}$ injection (Yangzhou Zhongbao Pharmaceutical Co., Ltd., SFDA approval no. H32024805) was used for treatment. The first loading dose was $8 \mathrm{~g} / \mathrm{h}$ intravenous drip, followed by $1-2 \mathrm{~g} / \mathrm{h}$ maintenance treatment until $12-24 \mathrm{~h}$ after uterine contraction inhibition, and the blood magnesium concentration was maintained at $2-3.5 \mathrm{mmol} / \mathrm{l}$; at the same time, they were given AT tablets orally (Changzhou Siyao Pharmaceutical Co., Ltd., SFDA approval no. H20113293), one tablet $(5 \mathrm{mg})$ each time, three times a day, until 37 weeks of pregnancy or childbirth. The research group was treated with AT+RD: $100 \mathrm{mg}$ of RD injection (Guangdong Xianqiang Pharmaceutical Co., Ltd., SFDA approval no. H20090302) mixed with $500 \mathrm{ml}$ of $5 \%$ glucose injection intravenously with an initial dose of $0.05 \mathrm{mg} / \mathrm{min}$ and an addition of $0.05-0.35 \mathrm{mg} / \mathrm{min}$ per minute until $0.10-0.40 \mathrm{mg} / \mathrm{min}$. The treatment was maintained until 12-24 h after uterine contraction was inhibited. At the same time, oral administration of AT tablets was the same as that of the control group for the same number of times and dose until 37 weeks of pregnancy or childbirth.

Observation indicators. General information of patients were collected, including age, height, weight, and gestational weeks. Enzyme-linked immunosorbent assay (Shanghai Xinfan Biotechnology Co., Ltd., XF130618) was used to detect the changes in the expression levels of IL-17, IL-10 and IL-6 in peripheral blood of patients before and after treatment. Prolonged pregnancy time, success rate of fetal protection and average delivery time of patients were recorded. The adverse pregnancy conditions of patients in the two groups were compared, including the Apgar score (12), birth weight and adverse conditions of the newborns, and postpartum hemorrhage and postpartum hospital stays of the research group were recorded.

Statistical methods. SPSS 19.0 (Asia Analytics Formerly SPSS China) was used for analysis. Measurement data were expressed as [n (\%)], and comparison of the rates between the two groups adopted $\chi^{2}$ test. Enumeration data were expressed as mean $\pm \mathrm{SD}$. Comparison between the two groups was conducted by independent-samples t-test, comparison at different time points in the group was conducted by repeated measures analysis of variance, and back testing was conducted by LSD test. A P $<0.05$ was considered to indicate a statistically significant difference.

\section{Results}

General information. The gestational weeks of patients in the two groups were between 27 and 33 weeks, and there was no significant difference in age, height, weight, gestational weeks and mean arterial pressure between them $(\mathrm{P}>0.05)$ (Table I).

Analysis of pregnancy. The fetus protection rate in the research group was significantly higher than that in the control group, and the difference was statistically significant $(\mathrm{P}<0.05)$. The prolonged pregnancy time in the research group was significantly better than that in the control group $(\mathrm{P}<0.05)$. The average delivery time in the research group was also higher than that in the control group $(\mathrm{P}<0.05)$ (Table II).

Analysis of inflammatory factors in peripheral blood. After treatment, the levels of IL-17, IL-10 and IL-6 in serum of the two groups were significantly lower than those before treatment $(\mathrm{P}<0.05)$. The expression levels of IL-17, IL-10 and IL-6 in serum of the research group were significantly lower than those of the control group $(\mathrm{P}<0.05)$ (Table III).

Analysis of Apgar score and birth weight of newborns. Apgar scores of newborns in research group and control group were $9.48 \pm 0.26$ and $8.97 \pm 0.18$, respectively, and birth weight was $3054.51 \pm 641.98 \mathrm{~g}$ and $2423.26 \pm 756.10 \mathrm{~g}$, respectively. Apgar scores and neonatal weight of patients in the research group were significantly higher than those in the control group, and the difference was statistically significant $(\mathrm{P}<0.05)$ (Fig. 1).

Analysis of adverse reactions of patients during treatment. During treatment, the number of patients with adverse reactions such as headache, chest discomfort, myasthenia and respiratory depression in the research group were $6(5.66 \%)$, $6(5.66 \%), 4(3.77 \%)$ and $5(4.72 \%)$, while the number of patients with adverse reactions in the control group were 16 (16\%), 14 (14\%), $14(14 \%)$ and $15(15 \%)$, respectively. The proportion of patients in the research group with adverse reactions was significantly lower than that in the control group, and the difference was statistically significant $(\mathrm{P}<0.05)$ (Fig. 2). 
Table I. General information.

\begin{tabular}{|c|c|c|c|c|}
\hline & Control group $(n=100)$ & Research group $(n=106)$ & $\chi^{2} / \mathrm{t}$ & P-value \\
\hline Age & $27.42 \pm 5.65$ & $27.68 \pm 5.49$ & 0.335 & 0.738 \\
\hline Height $(\mathrm{cm})$ & $158.57 \pm 5.65$ & $159.14 \pm 5.84$ & 0.735 & 0.463 \\
\hline Weight (kg) & $55.36 \pm 5.48$ & $54.69 \pm 5.98$ & 0.837 & 0.404 \\
\hline Gestational weeks (week) & $29.68 \pm 2.89$ & $29.44 \pm 3.10$ & 0.574 & 0.567 \\
\hline Mean arterial pressure $(\mathrm{mmHg})$ & $80.56 \pm 15.44$ & $82.67 \pm 14.96$ & 0.996 & 0.320 \\
\hline Cervical length (mm) & $13.42 \pm 4.26$ & $13.56 \pm 4.01$ & 0.243 & 0.808 \\
\hline Abdominal circumference $(\mathrm{cm})$ & $24.84 \pm 2.26$ & $24.66 \pm 2.37$ & 0.557 & 0.578 \\
\hline $\begin{array}{l}\text { Fetal heart rate } \\
\text { (times/min) }\end{array}$ & $120.65 \pm 21.77$ & $123.85 \pm 20.64$ & 1.803 & 0.280 \\
\hline History of premature labor [n (\%)] & & & 0.011 & 0.918 \\
\hline Yes & $54(54)$ & $58(54.72)$ & & \\
\hline No & $46(46)$ & $48(45.28)$ & & \\
\hline
\end{tabular}

Table II. Analysis of pregnancy.

\begin{tabular}{|c|c|c|c|c|}
\hline & Control group $(n=100)$ & Research group $(n=106)$ & $\chi^{2} / \mathrm{t}$ & P-value \\
\hline Fetal protection $[\mathrm{n}(\%)]$ & & & 4.903 & 0.027 \\
\hline Success & $85(85)$ & $98(92.45)$ & & \\
\hline Failure & $15(15)$ & $8(7.55)$ & & \\
\hline Prolonged pregnancy time (days) & $21.54 \pm 18.68$ & $34.68 \pm 23.58$ & 4.416 & $<0.001$ \\
\hline Average delivery time (weeks) & $35.21 \pm 3.68$ & $37.54 \pm 3.86$ & 4.429 & $<0.001$ \\
\hline
\end{tabular}
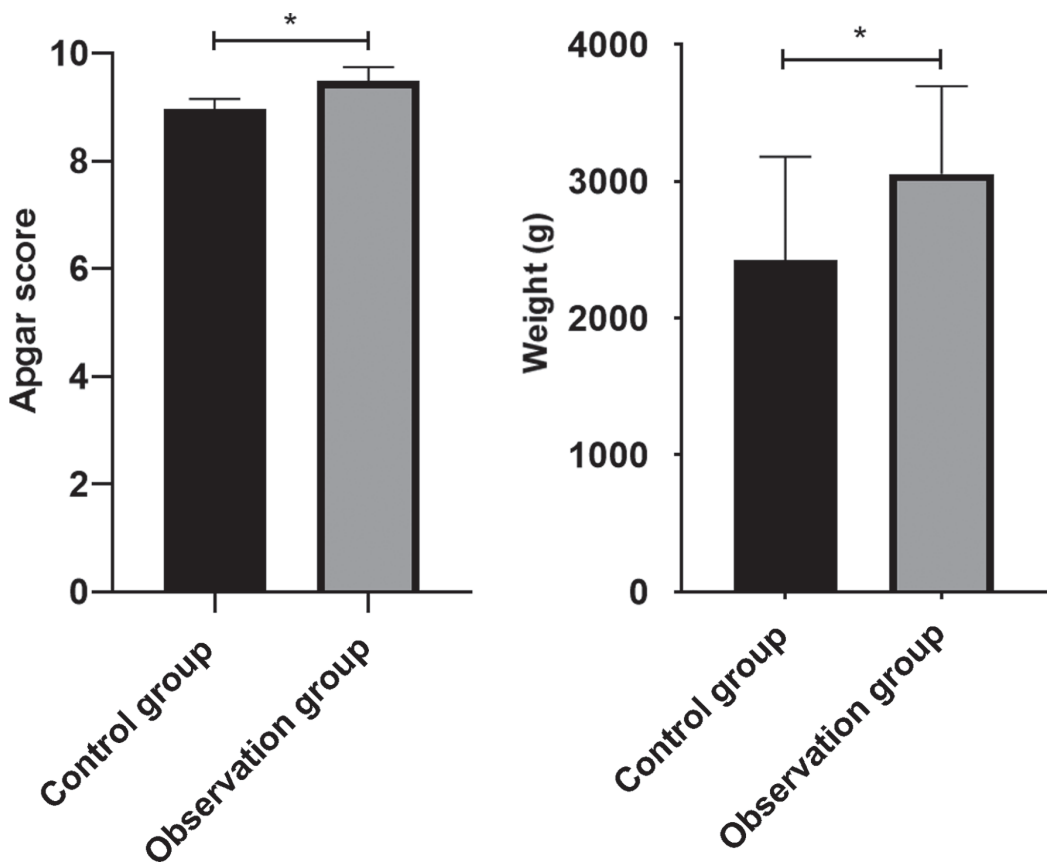

Figure 1. Analysis of Apgar score and birth weight of newborns. Apgar scores and birth weight in the research group were significantly higher than those in the control group. ${ }^{*} \mathrm{P}<0.05$.

Analysis of adverse factors. There were 2 cases of neonatal death in the control group, but none in the research group, and no significant difference. However, the newborns in the research group with malformation and asphyxia were significantly fewer than those in the control group, and the difference was statistically significant $(\mathrm{P}<0.05)$ (Table IV). 
Table III. Analysis of inflammatory factors in peripheral blood (pg/ml).

\begin{tabular}{lccrr}
\hline & Control group $(\mathrm{n}=100)$ & Research group $(\mathrm{n}=106)$ & $\mathrm{t}$ & P-value \\
\hline IL-17 & & & & \\
Before treatment & $37.25 \pm 8.67$ & $38.47 \pm 8.47$ & 1.021 & 0.308 \\
After treatment & $29.68 \pm 7.38^{\mathrm{a}}$ & $22.51 \pm 6.68^{\mathrm{a}}$ & 7.318 & $<0.001$ \\
IL-10 & & & 0.620 & 0.536 \\
Before treatment & $56.67 \pm 12.45$ & $57.58 \pm 13.22$ & 7.814 & $<0.001$ \\
After treatment & $46.62 \pm 12.84^{\mathrm{a}}$ & $32.74 \pm 12.65^{\mathrm{a}}$ & & 0.529 \\
IL-6 & & & 0.630 & $<0.001$ \\
Before treatment & $58.24 \pm 12.65$ & $57.09 \pm 13.49$ & 6.248 & \\
After treatment & $45.25 \pm 11.68^{\mathrm{a}}$ & $34.68 \pm 12.55^{\mathrm{a}}$ & & \\
\hline
\end{tabular}

${ }^{\mathrm{a}} \mathrm{P}<0.05$, compared with the same group before treatment.

Table IV. Analysis of neonatal adverse events [n (\%)].

\begin{tabular}{lcccr}
\hline & Control group $(\mathrm{n}=100)$ & Research group $(\mathrm{n}=106)$ & $\chi^{2}$ & P-value \\
\hline Death & $2(2.00)$ & 0 & 2.020 & 0.155 \\
Malformation & $5(5.00)$ & 0 & 5.229 & 0.022 \\
Asphyxia & $8(8.00)$ & $2(1.89)$ & 3.914 & 0.048 \\
\hline
\end{tabular}

Table V. Comparison of postpartum hemorrhage and postpartum hospital stays.

\begin{tabular}{lccrc}
\hline & Control group $(\mathrm{n}=100)$ & Research group $(\mathrm{n}=106)$ & $\chi^{2}$ & P-value \\
\hline Postpartum hemorrhage (ml) & $270.52 \pm 34.66$ & $164.85 \pm 25.67$ & 24.748 & $<0.001$ \\
Postpartum hospital stays (days) & $12.63 \pm 4.62$ & $8.52 \pm 3.54$ & 7.113 & $<0.0011$ \\
\hline
\end{tabular}

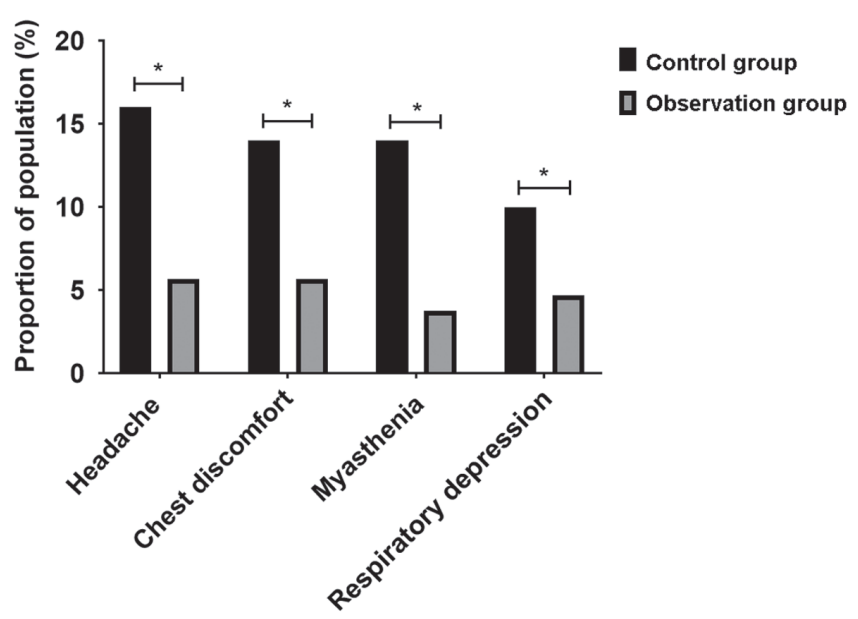

Figure 2. Analysis of adverse reactions of patients during treatment. Headache, chest discomfort, myasthenia and respiratory depression in the research group were significantly fewer than those in the control group. ${ }^{*} \mathrm{P}<0.05$.

Comparison of postpartum hemorrhage and postpartum hospital stays. Postpartum hemorrhage and postpartum hospital stays in the research group were significantly fewer than those in the control group, and the difference was statistically significant $(\mathrm{P}<0.05)$ (Table $\mathrm{V})$.

\section{Discussion}

TPTL is the main cause of perinatal morbidity and mortality in many countries, including the USA. Neonatal mortality, respiratory distress syndrome, intraventricular hemorrhage and other diseases are negatively correlated with gestational age at birth (13), and a study indicates that TPTL is a risk factor for impaired cognitive development at the age of 2 years. Cognitive ability of premature children is significantly lower than that of full-term children (14). TPTL seriously threatens the life and health of newborns and affects cognitive growth. Therefore, clinical treatment for TPTL requires better efficacy. Some studies have pointed out that AT can effectively prolong the pregnancy time of TPTL patients and can effectively reduce the messenger nucleotide level of oxytocin receptor (15). In addition, progesterone has a limited effect on acute uterine contraction, but it may play a role in preventing premature delivery or be regarded as a sensitizer of other uterine contraction agents (16). RD, as the only drug approved by the US 
Food and Drug Administration for anti-uterine contraction, has significant anti-uterine contraction efficacy on TPTL (17). There are many clinical reports on the treatment of TPTL with combination drugs. For example, RD combined with nifedipine can prolong pregnancy $>7$ days more effectively than RD alone (18), and there is no obvious difference in the efficacy and adverse reactions between $\mathrm{RD}$ and $\mathrm{MgSO}_{4}$ (19). However, there are few reports on AT combined with RD in the treatment of TPTL. Therefore, through prospective analysis, this study explored the efficacy of AT combined with $\mathrm{RD}$ in the treatment of TPTL and its influence on inflammatory factors in peripheral blood, so as to provide reference for clinical treatment of TPTL.

This study showed that after treatment, the pregnancy rate, prolonged pregnancy time and average delivery time in the research group were significantly higher than those in the control group. The Apgar score and neonatal weight of patients in the research group were significantly better than those in the control group. During treatment, the adverse reactions of patients in the research group and overall adverse conditions of newborns were significantly better than those in the control group.

Under normal circumstances, embryos are not rejected by mothers, which depends on the immune tolerance of mother-fetus interface and the balance between cytokines. Once this immune tolerance pattern is destroyed, habitual abortion will occur (20). The cervical vagina or intrauterine infection process during pregnancy is an extremely fragile state for the mothers and fetuses. The immune defense process induces the pro-inflammatory environment and damages the immune privilege in the uterine cavity. Nearly $30 \%$ of premature women have microbial invasion or inflammation in the amniotic cavity, which results in increase of interleukin and tumor necrosis factor, leading to disruption of fetal tolerance (21). Progesterone has a strong immunoregulation effect and is of great significance to physiological immune tolerance when lying in bed (22). Progesterone has an effect on interleukin production in vaginal and cervical epithelial cells, inhibits vaginal epithelial cell base and bacterial stimulation of interleukin production, and induces changes in the concentration of inflammatory factors in cervical secretions $(23,24)$. We studied and measured the changes of IL-17, IL-10 and IL-6 levels in serum of the two groups. Our study indicated that the levels of IL-17, IL-10 and IL-6 in serum of the two groups after treatment were significantly lower than those before treatment. The expression levels of IL-17, IL-10 and IL-6 in serum of the research group after treatment were significantly lower than those in the control group. AT combined with RD can effectively reduce the level of inflammatory factors, prevent the immune destruction of the body and effectively maintain the body balance. This is one of the reasons why the efficacy of patients in the research group is obviously better than that of the control group. In addition, this study indicated that IL-6, IL-8 and IL-10 might be developed as factors for predicting TPTL in the future, which also verified the role of inflammatory factors in TPTL (25).

In the present study, we obtained results showing that the effects of AT combined with RD on TPTL were better than that of AT combined with $\mathrm{MgSO}_{4}$. However, further studies are necessary with larger sample size for confirmation.
In conclusion, AT combined with RD in the treatment of TPTL can significantly reduce the expression levels of IL-17, IL-10 and IL-6, reduce adverse pregnancy conditions, prolong gestational weeks, and has higher safety and better application value.

\section{Acknowledgements}

Not applicable.

\section{Funding}

No funding was received.

\section{Availability of data and materials}

The datasets used and/or analyzed during the current study are available from the corresponding author on reasonable request.

\section{Authors' contributions}

QL wrote the manuscript. QL and CL conceived and designed the study. QL and HJ were responsible for the collection and analysis of the experimental data. CL and HJ interpreted the data and drafted the manuscript. QL and CL revised the manuscript critically for important intellectual content. All authors read and approved the final manuscript.

\section{Ethics approval and consent to participate}

The study was approved by the Ethics Committee of Qingpu Branch of Zhongshan Hospital Affiliated to Fudan University (Shanghai, China). Patients who participated in this research had complete clinical data. Signed informed consents were obtained from the patients or the guardians.

\section{Patient consent for publication}

Not applicable.

\section{Competing interests}

The authors declare that they have no competing interests.

\section{References}

1. Roos C, Schuit E, Scheepers HC, Bloemenkamp KW, Bolte AC, Duvekot HJ, van Eyck J, Kok JH, Kwee A, Merién AE, et al; for APOSTEL-II Study Group: Predictive factors for delivery within 7 days after successful 48-hour treatment of threatened preterm labor. AJP Rep 5: e141-e149, 2015.

2. Heng YJ, Taylor L, Larsen BG, Chua HN, Pung SM, Lee MW, Tucholska M, Tate S, Kupchak P, Pennell CE, et al: Albumin decrease is associated with spontaneous preterm delivery within $48 \mathrm{~h}$ in women with threatened preterm labor. J Proteome Res 14: 457-466, 2015.

3. Melamed N, Hiersch L, Gabbay-Benziv R, Bardin R, Meizner I, Wiznitzer A and Yogev Y: Predictive value of cervical length in women with twin pregnancy presenting with threatened preterm labor. Ultrasound Obstet Gynecol 46: 73-81, 2015.

4. Carter J, Tribe RM, Shennan AH and Sandall J: Threatened preterm labour: Women's experiences of risk and care management: A qualitative study. Midwifery 64: 85-92, 2018. 
5. Wagner P, Sonek J, Heidemeyer M, Schmid M, Abele H, Hoopmann M and Kagan KO: Repeat measurement of cervical length in women with threatened preterm labor. Geburtshilfe Frauenheilkd 76: 779-784, 2016 (In German).

6. Malhotra N, Garg R, Malhotra N and Malhotra J: Oral allylestrenol: A pregnancy-supporting progestogen. J South Asian Fed Obstet Gynecol 9: 297-303, 2017.

7. Joshi P and Nayak A: Role of progesterone in threatened preterm labour. Indian Obstetr Gynaecol 4: 16-23, 2014.

8. Dewailly D, Lujan ME, Carmina E, Cedars MI, Laven J, Norman RJ and Escobar-Morreale HF: Definition and significance of polycystic ovarian morphology: A task force report from the Androgen Excess and Polycystic Ovary Syndrome Society. Hum Reprod Update 20: 334-352, 2014.

9. Takekawa D, Jinushi K, Kitayama M and Hirota K: Rebound hyperkalemia after cessation of ritodrine in a parturient undergoing cesarean section. JA Clin Rep 3: 3, 2017.

10. Yuan JL and Yang L: Efficacy observation of allylestrenol combined with ritodrine in treatment of habitual abortion Zhongguo Yiyuan Yongyao Pingjia Yu Fenxi 15: 1580-1582, 2015 (In Chinese)

11. Zhu RY, Wong YC and Yong EL: Sonographic evaluation of polycystic ovaries. Best Pract Res Clin Obstet Gynaecol 37: 25-37, 2016.

12. Iliodromiti S, Mackay DF, Smith GC, Pell JP and Nelson SM: Apgar score and the risk of cause-specific infant mortality: A population-based cohort study. Lancet 384: 1749-1755, 2014.

13. Berghella V, Palacio M, Ness A, Alfirevic Z, Nicolaides KH and Saccone G: Cervical length screening for prevention of preterm birth in singleton pregnancy with threatened preterm labor: Systematic review and meta-analysis of randomized controlled trials using individual patient-level data. Ultrasound Obstet Gynecol 49: 322-329, 2017.

14. Paules C, Pueyo V, Martí E, de Vilchez S, Burd I, Calvo P and Oros D: Threatened preterm labor is a risk factor for impaired cognitive development in early childhood. Am J Obstet Gynecol 216: 157. e1-157. e7, 2017.

15. Xu YJ, Ren LD, Zhai SS, Ran LM, Hu LL, Luo XH, Hong T, Liu R, Yu YR and Ban YJ: OXTR and ZEB1 expression before and after progesterone dosing in pregnant women with threatened premature labor. Eur Rev Med Pharmacol Sci 21: 3164-3168, 2017.

16. van Vliet EO, Boormans EM, de Lange TS, Mol BW and Oudijk MA: Preterm labor: Current pharmacotherapy options for tocolysis. Expert Opin Pharmacother 15: 787-797, 2014.
17. Kareli D, Pouliliou S, Liberis A, Nikas I, Psillaki A, Kontomanolis E, Nikolettos N, Galazios G and Lialiaris T: Genotoxic effect of tocolytic drug ritodrine in combination with smoking during pregnancy. J Matern Fetal Neonatal Med 29: 3496-3505, 2016.

18. Kim MJ, Hwang I, Bae JY and Seong WJ: The influence of ritodrine alone or in combination with nifedipine on maternal cardiovascular side effects and pregnancy outcomes. Clin Exp Obstet Gynecol 41: 537-540, 2014.

19. Kim MK, Lee SM, Oh JW, Kim SY, Jeong HG, Kim SM, Park CW, Jun JK, Hahn SK and Park JS: Efficacy and side effect of ritodrine and magnesium sulfate in threatened preterm labor. Obstet Gynecol Sci 61: 63-70, 2018.

20. Nigro G, Mazzocco M, Mattia E, Di Renzo GC, Carta G and Anceschi MM: Role of the infections in recurrent spontaneous abortion. J Matern Fetal Neonatal Med 24: 983-989, 2011.

21. Garcia-Ruíz G, Flores-Espinosa P, Preciado-Martínez E, Bermejo-Martínez L, Espejel-Nuñez A, Estrada-Gutierrez G, Maida-Claros R, Flores-Pliego A and Zaga-Clavellina V: In vitro progesterone modulation on bacterial endotoxin-induced production of IL-1 $\beta$, TNF $\alpha$, IL-6, IL-8, IL-10, MIP-1 $\alpha$, and MMP-9 in pre-labor human term placenta. Reprod Biol Endocrinol 13: 115, 2015.

22. Carp HJA: Progestogens and pregnancy loss. Climacteric 21: 380-384, 2018

23. Koucký M, Malíčková K, Cindrová-Davies T, Smíšek J, Vráblíková H, Černý A, Šimják P, Slováčková M, Pařízek A and Zima T: Prolonged progesterone administration is associated with less frequent cervicovaginal colonization by Ureaplasma urealyticum during pregnancy - Results of a pilot study. J Reprod Immunol 116: 35-41, 2016.

24. Alimohamadi S, Javadian P, Gharedaghi MH, Javadian N, Alinia $\mathrm{H}$, Khazardoust S, Borna $\mathrm{S}$ and Hantoushzadeh $\mathrm{S}$ : Progesterone and threatened abortion: A randomized clinical trial on endocervical cytokine concentrations. J Reprod Immunol 98: 52-60, 2013

25. Shah J and Baxi B: Identification of biomarkers for prediction of preterm delivery. J Med Soc 30: 3-14, 2016 